\title{
Construção da Leitura/Escrita em Língua de Sinais de Crianças Surdas em Ambientes Digitais
}

\author{
Creice Barth \\ Universidade Federal do RS-Brasil - creice@ gmail.com \\ Lucila M.C.Santarosa \\ Universidade Federal do RS- Brasil- lucila.santarosa@terra.com.br \\ Fernanda Chagas Schneider \\ Universidade Federal do RS -Brasil- ferchsc@ yahoo.com.br \\ Alessandro Antunes Silva \\ Universidade Federal do RS-Brasil- aleantunesrs@gmail.com
}

\section{RESUMO}

Este trabalho apresenta o resultado de uma pesquisa sobre os processos e estratégias que crianças surdas utilizam para construção da escrita/leitura na língua de sinais, assim como examina a partir de que momento a criança surda começa a interpretar a sua escrita em língua de sinais e, por fim, verifica quais os benefícios que as crianças surdas obtêm ao interagirem com seus pares na construção dessa escrita, mediada em ambientes digitais, neste caso, um teclado virtual para a escrita da língua de sinais. Ferreiro e Teberosky (1999),Vygotsky (2001 e 2003), entre outros autores, foram utilizados como aportes teóricos para o desenvolvimento desta investigação. As contribuições deste trabalho apontam para a necessidade de modificar o olhar sobre as práticas pedagógicas no que diz respeito à alfabetização de crianças surdas, ainda em português tendo como aporte estudos teóricos sobre a psicogênese da língua escrita tal qual se processa em crianças ouvintes.

\section{PALAVRAS-CHAVE:}

Escrita da Língua de Sinais, construção do processo de escrita e leitura, educação de surdos, teclado virtual

\section{Construction of Reading/Writing in Language of Singns of Deaf Children in Digital Environments}

\begin{abstract}
This paper presents results of research about the processes and strategies that deaf children use to build the read / write in sign language, and examines the time at which deaf children begin to interpret your writing in sign language, and Finally, check what benefits deaf children get to interact with their others in the construction of this writing, mediated digital environments, in this case, a virtual keyboard for writing sign language. Ferreiro \& Teberosky(1999), Vygotsky (2001 and 2003), among others, were used as theoretical support for the development of this research. The contributions of this study point to the need to modify the look on practice with regard to the literacy of deaf children, even in portuguese as a support and theoretical studies of the psychogenesis written language as it is processed in hearing children.
\end{abstract}

\section{KEY-WORDS}

Writing of Sign Language, construction of the process of writing and reading, deaf education, virtual keyboard 


\section{INTRODUÇÃO}

Podemos perceber atualmente a necessidade de mais pesquisas sobre o processo de aquisição da escrita da língua de sinais de crianças surdas para que possamos trazer mais evidências desse processo e, com isto, possibilitar a oferta de subsídios a professores alfabetizadores, sendo também importante que esses subsídios sejam reconhecidos e utilizados em todo o país. Atualmente, pesquisas em maior escala são realizadas em American Sign Lenguage (Língua de Sinais Americana), porém no que se refere à aquisição da proficiência em língua de sinais, estudos sobre sua representação escrita ainda são escassos.

Ao considerar esta emergência, podemos contar com a utilização de ambientes digitais, já que são inegáveis as várias possibilidades de seu uso no processo de ensino e de aprendizagem, inclusive na educação de surdos, uma vez que podemos ter acesso a vários recursos multimídia e de customização desses para atender às necessidades de crianças surdas.

A partir destas observações, investigamos as etapas e as estratégias que as crianças surdas utilizam para construir a escrita e, consequentemente a leitura, em língua de sinais, assim como em que momento começam a interpretar essa escrita, e por fim, quais os processos que se evidenciam nessa construção entre seus pares, utilizandose do aporte de ambientes digitais e seus recursos visuais ilimitados.

\section{AQUISIÇÃO DA LÍNGUA DE SINAIS EM CRIANÇAS SURDAS}

Vygotsky rejeitou a abordagem popular na União Soviética de sua época, baseada unicamente na evolução biológica, pois não acreditava que o desenvolvimento de uma criança com necessidades especiais obedecia a suas próprias leis particulares, mas sim que as leis do desenvolvimento eram as mesmas para todas as crianças. Ressaltava, ainda, a relevância dos aspectos sociais da aprendizagem, defendendo dentro da abordagem educacional, a importância não só da pedagogia, mas do meio capaz de desenvolver e aperfeiçoar as habilidades pedagógicas, pois para o autor, toda criança é considerada educável, já que "dentro de um processo geral de desenvolvimento duas linhas qualitativamente diferentes do desenvolvimento, diferindo quanto à sua origem: de um lado, os processos elementares que são de origem biológica; de outro, as funções psicológicas superiores, de origem sócio-cultural"(Vygotski, 2003, p. 61). Acrescenta que "...a história do comportamento da criança nasce do entrelaçamento dessas duas linhas" (Vygotski, 2003, p. 10).

O princípio básico da relação interpessoal está embasado na comunicação entre os indivíduos e, para isso, a comunicação deve ter um significado social; para tanto, é necessário compreender a natureza do significado da palavra para Vygotsky, “...a palavra nunca se refere a um objeto isolado mas a todo um grupo ou classe de objetos. Por esta razão, cada palavra é uma generalização latente, toda palavra já generalizada e, em termos psicológicos, é antes de tudo uma generalização" (Vygotski, 2001, p. 9).

Nessa dimensão, para que haja compreensão na comunicação social, é imprescindível que nesse fenômeno venha acompanhado de significado, já que neste reino e no reino do pensamento, "sem significado a palavra não é palavra mas som vazio" (Vygotski, 2003, p.125). Para o autor, o meio de comunicação é o signo, e a palavra é o som, então, a comunicação sem signo é tão impossível quanto sem significado, pois, num contexto sócio-histórico, o mundo da experiência deve ser generalizado e simplificado a fim de que possa ser possível simbolizá-lo.

Com isso, se o desenvolvimento do pensamento e o da linguagem dependem de instrumentos do pensamento e também das experiências socioculturais do sujeito, é importante salientar que o pensamento desse depende do domínio que ele tem sobre os 
meios sociais do seu pensamento e da sua linguagem, ou seja, passa do comportamento biológico para o desenvolvimento do comportamento histórico-social. A análise de Vygotsky ressalta a importância do poder semiótico e mediador da linguagem, sendo “...a concepção do significado da palavra como unidade tanto do pensamento generalizante como do intercâmbio social é de incalculável valor para o estudo do pensamento e da linguagem. Permite uma verdadeira análise genético-causal, um estudo sistemático das relações entre o crescimento da capacidade de pensar da criança e seu desenvolvimento social (Daniels, 2003). No que se refere a essa teoria sobre educação de surdos, diz Fernandes: “...esta constatação infere à aquisição da língua um lugar privilegiado não apenas no que se refere ao processo de comunicação, mas também ao desenvolvimento cognitivo. Afirmamos, também, que através da aquisição de um sistema simbólico, como é o da língua o ser humano descobre novas formas de pensamento, transformando sua concepção de mundo. Tendo em vista estas colocações, torna-se bastante claro, portanto, que propiciar à pessoa surda a exposição a uma língua o mais cedo possível, obedecendo às fases naturais de sua aquisição é fundamental ao seu desenvolvimento" (Fernandes, 2005).

Diante disso, mesmo para crianças surdas que consigam desenvolver uma linguagem respeitando as regras gramaticais de uma sociedade ouvinte, a simples memorização das palavras e a sua associação com os objetos não conseguem, por si sós, formar conceitos, pois eles estão apenas sendo reproduzidos, já que a construção de conceitos exige uma operação complexa voltada para solução de problemas.

Baseada na teoria sociointeracionista, a autora relata que, para a formação de conceitos, o signo é a palavra e passa a ser o meio na formação do conceito, sendo, posteriormente, o símbolo. Quadros afirma que “...ao investirem anos de vida na oralização de uma criança surda, esta apenas consegue capturar através da leitura labial, cerca de $20 \%$ da mensagem e, além disso, sua produção oral, normalmente, não é compreendida por pessoas que não convivem com elas" (Quadros, 1997, p. 23)

Conforme esses estudos, Karnopp e Quadros (2001) salientam que crianças surdas de nascença, tendo acesso a uma língua espaço-visual proporcionada por surdos, conseguirão desenvolver uma linguagem sem deficiência alguma. Também referem que crianças surdas filhas de pais surdos conseguem alcançar um melhor desempenho acadêmico do que crianças surdas filhas de pais ouvintes.

\section{A CRIANÇA SURDA NA FASE INICIAL DA ESCRITA DA LÍNGUA DE SINAIS}

Ferreiro e Teberosky, em seus estudos epistemológicos baseados no Construtivismo de Piaget sobre a alfabetização, observaram os diferentes níveis desse processo, em que as crianzas, interagindo com a escrita passavam a construir hipóteses e relações de significação que pareceram ser comuns a todas as crianças. Para as autoras, “...quando uma criança escreve tal como acredita que poderia ou deveria escrever certo conjunto de palavras, está oferecendo um valiosíssimo documento que necessita ser interpretado para poder ser avaliado. Essas escritas infantis têm sido consideradas, displicentemente, como garatujas, 'puro jogo'. O resultado de fazer 'como se' soubesse escrever. Aprender a lê-las - isto é interpretá-las - é um longo aprendizado que requer atitude teórica definida..." (Ferreiro \& Teberosky, 1999, p. 17)

Assim, na alfabetização de surdos, toda energia, segundo Quadros (1997), está canalizada para a observação dos níveis propostos por Ferreiro e Teberosky, isto é, em níveis com base em sistemas de escrita alfabética. Ou seja, os níveis pré-silábico, silábico, silábico-alfabético e alfabético (com suas subdivisões). Segundo Quadros 
(1997), vários professores alfabetizadores de crianças surdas procuraram visualizar esse mesmo processo.

É importante que busquemos resultados da pesquisa de Ferreiro e Teberosky intitulada Psicogênese da Língua Escrita, devido ao seu grau de importância para a alfabetização de crianças ouvintes, porém, no processo de aquisição da escrita em crianças surdas, ela não serve como parâmetro. Acreditamos na sua colaboração no que tange à importância de perceber os critérios de observações, como níveis de estágios, estratégias, processos e hipóteses sobre a escrita construídas pelas crianças ouvintes e suas relações de significados com essa mesma escrita. Mas, destacamos que, para crianças surdas, a representação da escrita em nada está relacionada com as representações sonoras, visto que "sonoras para surdos devem ser visuais" (Quadros, 1997, p 74) valendo salientar que os níveis e estratégias descobertos por Ferreiro e Teberosky não podem ser comparados aos níveis e estratégias que crianças surdas desenvolvem na construção de sua escrita e leitura no sistema SignWriting.

Com isso, a pesquisa sobre aquisição da escrita em crianzas surdas é de suma importância, pois há alfabetizadores de crianças surdas que ainda procuram respostas com base em estudos de Ferreiro e Teberosky, contudo, segundo Quadros (1997) eles encontram um "buraco-negro" ao compararem ambos os processos de alfabetização [9]. Mesmo que haja consenso de que há autonomia na escrita, as autoras identificaram os processos de alfabetização alfabética em crianças que estabelecem uma relação de significação entre o que está escrito e o que é dito ou ouvido. Quadros ainda salienta que “...a escrita alfabética da língua portuguesa no Brasil não serve para representar significação com conceitos elaborados na LIBRAS (Língua Brasileira de Sinais), uma língua visual espacial. Um grafema, uma silaba, uma palavra escrita no português não apresenta nenhuma analogia com um fonema, uma sílaba e uma palavra na LIBRAS, mas sim com o português falado. A língua portuguesa não é uma língua natural da criança surda." (Quadros, 1997, p. 5)

Outra dificuldade é que Teberosky fundamenta que a escola percebe a construção da escrita sendo realizada de forma individual, para o próprio sujeito. Entretanto, esquece que essa construção é o resultado "do esforço coletivo da humanidade, cuja função é social. O modo como a criança aprende a escrever segue o caminho da apropriação individual de um fenômeno social.” (Teberosky, 2003, p. 125)

Ao pensarmos no desenvolvimento da linguagem em crianças ouvintes, na concepção de Vygotsky, a linguagem escrita é constituída por um sistema de signos "que se designam os sons e as palavras da linguagem falada, os quais, por sua vez, são signos das relações e entidades reais. Gradualmente, esse elo intermediário (a linguagem falada) desaparece e a linguagem escrita converte-se num sistema de signos que simboliza diretamente as entidades reais e as relações entre elas" (Vygotski, 2003). Ou seja, para o autor soviético, a escrita precisa ter um significado para as crianças, as quais precisam ser despertadas para uma necessidade intrínseca, e a escrita passará a ser incorporada a uma tarefa relevante para sua vida. "Só então poderemos estar certos que ela se desenvolverá não como hábito de mãos e dedos, mas como uma forma nova e complexa de linguagem" (Vygotski, 2003, p 152). Para o autor, o que se deve é ensinar a linguagem escrita e não apenas a escrita de letras, já que a linguagem escrita possui uma origem completa distinta e outra estrutura psicológica.

Vygotsky (2001), salienta que os instrumentos (escrita) são dirigidos ao mundo externo, com isso passam a conduzir o homem para o objeto de sua atividade. Nesse momento, a natureza é transformada como signo (linguagem escrita), assim, além de construir a relação entre os seres humanos, ainda influi psicologicamente na conduta do próprio sujeito, capaz de alterá-la e configurá-la como meio de atividade interna 
dirigida. Ao transpormos essas afirmações para alfabetização de crianças surdas, Silva diz que "a língua que o surdo tem como legítima e usa não é a mesma que serve como base ao sistema escrito, por ser um sistema visuomanual, portanto muito diferente do oral auditivo" (Silva, 2001, p. 48). Com isso, não podemos perceber a escrita como apenas uma habilidade motora, mas como um sistema formado por um conhecimento complexo.

Ao remeter esse processo de alfabetização para crianças surdas, percebemos que não se pode referir à construção da escrita em língua portuguesa em crianças surdas assim como é para crianças ouvintes, pois esta se dá na modalidade auditiva e fonoarticulatória, enquanto que a língua de sinais se dá de forma natural e primária do surdo como modalidade visual e quiroarticulatória. Segundo Capovilla, “... a criança surda encontra-se numa situação peculiar de descontinuidade entre os sistemas primário e secundário de representação linguística, entre a sinalização interna visual e quiroarticulatória com que ela se faz processamento interno e o sistema de escrita alfabético fonológico com que se espera que ela se expresse" (Capovilla, 2004, p. 258.).

Para Stumpf (2005), as crianças surdas que se comunicam por meio de sinais, precisam representar pela escrita sua fala, que neste caso é visuoespacial. Quando conseguem aprender uma escrita que é a representação de sua língua natural, essa terá a oportunidade de melhorar seu desenvolvimento cognitivo. Assim, "a criança transfere para sua nova língua o sistema de significados que já possui na sua própria língua e quando ela aprende a ver sua língua como um sistema específico entre muitos, passa a conceber seus fenômenos dentro de categorias mais gerais e isso leva à consciência das operações lingüísticas" (Stumpf, 2005, p.45)

A escrita de sinais é um sistema de escrita direta de sinais, ou seja, representação do sistema primário de comunicação da Língua Brasileira de Sinais, que é constituído por gramática, semântica, pragmática, sintaxe e outros que a fazem um instrumento linguístico completo para os surdos. Segundo Stumpf, “... o conhecimento do conceito metalingüístico supõe que para refletir sobre a língua é necessário poder colocar-se fora dela, poder observá-la, e isto está intimamente relacionado com a possibilidade de ler e escrever" (Stumpf, 2004, p. 146)
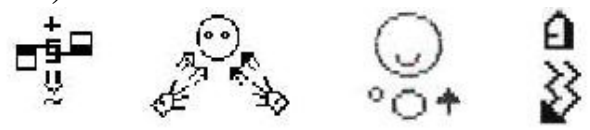

Figura 1. Escrita da língua de sinais no sistema SignWriting: Amizade, Atenção, Bom e Brasil

Após refletir sobre pesquisas e teorias da alfabetização, podemos observar que a questão pedagógica sobre alfabetização de surdos merece ser analisada observando dois aspectos. O primeiro trata do processo de construção individual do conhecimento, levando em conta as tentativas e hipóteses relativas à escrita como representação da fala (em sinais) e que analisa o "conflito cognitivo" no processo de aprendizagem e vê o erro como fundamentalmente construtivo no processo, considerando o processo de internalização dos papéis e funções sociais apontado por Vygotsky; o segundo considera a atividade mental da criança surda nesse processo de alfabetização (em sinais) como atividade discursiva que implica a elaboração conceitual pela palavra (sinal). Portanto, outro ponto é fundamental quando examinamos o nível de proficiência na própria língua das crianças surdas em fase escolar, já que muitas adquirem vocabulário em LIBRAS somente ao ingressarem na escola. Quadros afirma que "quanto à alfabetização, parece que as crianças surdas alfabetizam-se naturalmente quando em contato com o sistema escrito das línguas de sinais. Por outro lado, o processo de aquisição/aprendizagem do 
português não é essencial, mas é necessário na sociedade brasileira; assim sendo, os alunos surdos precisam adquirir o português escrito" (Quadros, 1997,p 87 )

Por fim, para que essas crianças possam praticar a leitura e a escrita, é importante que com a aquisição da escrita da língua de sinais como forma de registro, as escolas para surdos percebam a urgência de promover o desenvolvimento da aquisição da linguagem escrita em Língua Brasileira de Sinais, para que não continuem reproduzindo iletrados em sinais (Quadros, 2000).

\section{TECLADO VIRTUAL PARA A ESCRITA DA LÍNGUA DE SINAIS}

Após várias buscas por ambientes digitais que mediassem a construção da escrita da língua de sinais por crianças surdas, permitindo que as mesmas se apropriassem de suas funcionalidades e, ao mesmo tempo, conseguissem demonstrar suas estratégias e etapas nessa construção, verificamos que os softwares desenvolvidos até o momento para a escrita da língua de sinais no sistema SignWriting não contemplavam todas as características funcionais e não continham recursos digitais que favorecessem a observação por parte de pesquisadores, e a utilização por parte de profissionais da área da educação de surdos, de como a criança surda constrói a escrita e leitura da língua de sinais no sistema SignWriting.

Para o desenvolvimento desse teclado virtual utilizamos a tecnologia Flash versão 8.0. Esse software oferece uma interface que adiciona diversas ferramentas ao programador, como criação de recursos gráficos, entre eles imagens .gif e .jpg e filmes animados no formato .swf, e importação de arquivos externos, tais como vídeo e áudio, criados ou editados em outros programas. A versão 8 trouxe uma série de inovações, principalmente na linguagem ActionScript 2.0, que é orientada a objetos, contendo recursos como herança de propriedades, criação de classes e utilização de métodos. Por essas razões, escolhemos o Flash 8.0, pois é considerado, por especialistas, uma ótima ferramenta de autoria, já que possibilita desenvolver desde um simples jogo-da-velha ou um site, até softwares mais complexos.

Outra vantagem a destacar está no fato de que é um dos softwares de maior aceitação entre os usuários nos últimos anos, considerando-se que foi projetado para ser visualizado em páginas da Web, sendo com isto, a melhor escolha para desenvolvimento de material a ser disponibilizado na Internet.

A tecnologia Flash faz uso de vetores gráficos e compressão de arquivos de vídeo, o que faz com que o tamanho final fique menor do que comparado àqueles criados em outros programas facilitando, assim, seu uso junto à Internet.

\section{Apresentação das Telas e funcionalidade do Teclado Virtual para a escrita da Língua de Sinais}

A seguir, apresentamos o teclado virtual, com todos os seus elementos gráficos e suas diferentes possibilidades, como digitar na escrita da língua de sinais por meio do teclado convencional ou das teclas virtuais, e desenhar, como mostramos na Figura 2. Existem diferentes cores para que o usuário possa desenhar (Figura 3), a lixeira que limpa todo o desenho, o disquete para salvar o trabalho realizado, a borracha para apagar partes do desenho, o menu de ajuda para o vídeo instrutivo, o botão para ligar ou desligar a grade de apoio (em cinza), o botão de mais (+) ou menos (-) para o pincel e o botão de fechar o software (X), como mostra a Figura 4. 

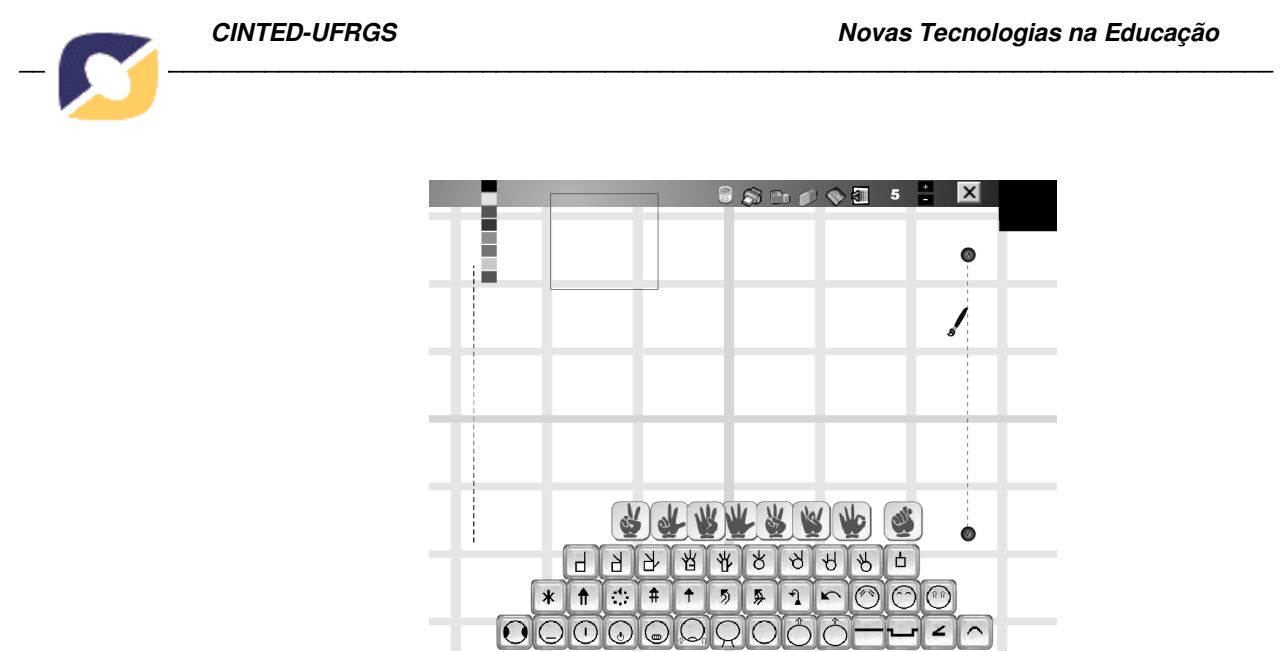

Figura 2. Tela inicial do Teclado Virtual

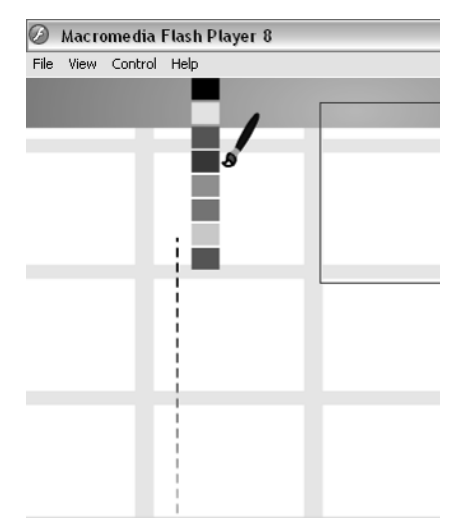

Figura 3. A ferramente pincel e a cartela de cores para desenhar ou escrever à mão livre.

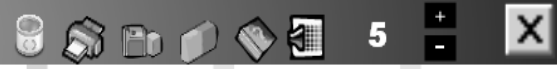

Figura 4. Tela do menu principal com as funcionalidades

Cada uma das teclas do teclado virtual abre um conjunto de símbolos que podem ser arrastados pela tela, duplicados, girados por meio da tecla Insert no teclado convencional e apagados com a seta voltar $(\leftarrow)$ também do teclado convencional. Já o quadro que se encontra na parte superior esquerda do software é o local onde são duplicados os símbolos.

A seguir, apresentamos o recurso de escrever por meio do teclado convencional do computador, utilizando a fonte SuttonBR e o pincel para desenho à mão livre.

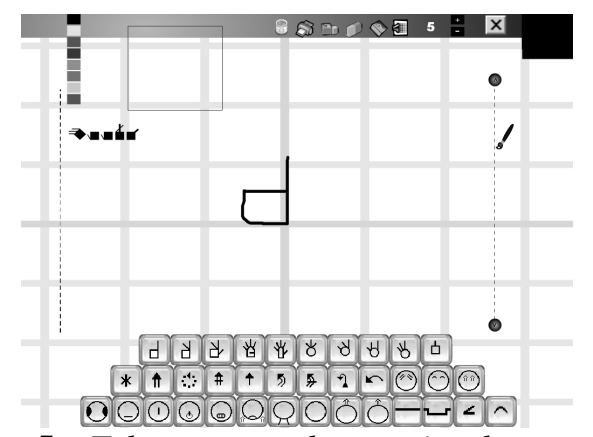

Figura 5. Tela mostrando o pincel e o teclado convencional para digitar, utilizando a fonte SuttonBR.

V. $7 \mathrm{~N}^{\circ}$ 3, dezembro, 2009 
Para realizar essas investigações, foram observadas quatro crianças de 7 a 12 anos de idade de uma escola de surdos da cidade de Porto Alegre/RS. Para identificarmos os sujeitos da pesquisa, utilizaremos as siglas JS, EM, AO e MV. As fases da construção da escrita da língua de sinais que se evidenciaram nesta pesquisa foram: desenho, desenho e escrita, relação da escrita com a linguagem gestual, subcategoria do uso da escrita como recurso mnemônico e início da escrita com significados. É importante salientar que relataremos as etapas mais relevantes nesse processo.

Durante as investigações, que duraram um total de seis meses, percebemos que duas crianças (EM e $\mathrm{AO}$ ) iniciaram as atividades fazendo representações gráficas através de desenhos, como apresentamos na figura a seguir:

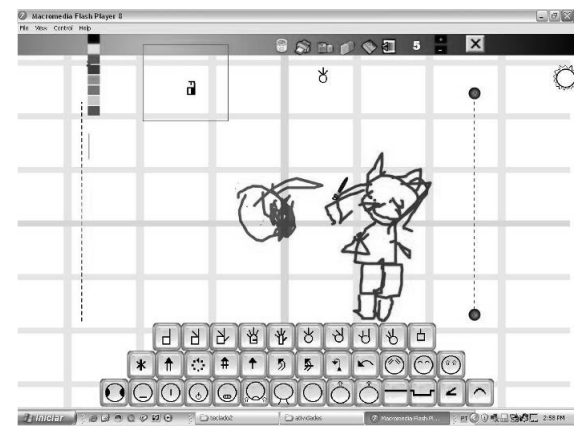

Figura 6. Atividade de EM registrada por meio de um desenho.

A cada atividade solicitada, o resultado se dava por meio de desenhos referentes à forma como observavam os objetos em questão. O que distingue esses dois sujeitos da pesquisa é de que AO não dominava vocabulário em LIBRAS, a comunicação era restrita, pois não havia muita compreensão do que estava sendo solicitado, e EM dominava a língua com fluência semelhante à de JS e MV, outros sujeitos da pesquisa. Enquanto AO e EM avançavam para a transição do desenho para a escrita, JS iniciava o processo de construção da transição do desenho para a escrita.

Observamos que seus desenhos apresentavam movimentos de mãos, configurações de mãos e expressão facial, contendo as unidades mínimas desse sistema. JS possuía fluência em LIBRAS para conversar, com um vocabulário vasto, que mantinha durante as sessões com EM e com a pesquisadora. EM só conseguiu escrever seu sinal e deixou de representá-lo com desenhos por meio da ajuda de JS, que atuou na Zona de Desenvolvimento Proximal de EM. O resultado da colaboração entre pares foi provocar uma evolução no desenvolvimento da construção da escrita por EM. Nas atividades que envolviam a interação entre pares, EM utilizava o pincel para registrar seu pensamento por meio do desenho, pois estava trabalhando em seu nível de desenvolvimento real, ou seja, sem a ajuda de outros e sem o fornecimento de "dicas", até ser ajudada por alguém mais experiente, nesse caso, JS. Contudo, não verificamos uma mudança de traços em seus registros até a interação com seu colega, pois ainda escolhia a ferramenta pincel para realizar as atividades. Percebemos, também, que EM utilizava mais a fala egocêntrica durante essas atividades do que naquelas em que realizava as atividades sozinha, sem a ajuda de alguém mais experiente. Para Vygotsky, “... a linguagem surge inicialmente como um meio de comunicação entre a criança e as pessoas em seu ambiente. Somente depois, quando da conversão em fala interior, ela vem a organizar o pensamento da criança, ou seja, torna-se uma função mental interna" (Vygotski, 2003). 
Diz ainda que a criança só é capaz de operar quando interage com outras pessoas em seu ambiente, utilizando-se da cooperação entre seus pares e que, "uma vez internalizados, esses processos tornam-se parte das aquisições do desenvolvimento independente da criança" (Vygotski, 2003).

AO passou a construir novos vocabulários, passando de pequenos sinais que representavam objetos para frases curtas, com uma compreensão maior da conversação entre pares. Deixou de utilizar a ferramenta pincel (fase do desenho com escrita) e passou para a escrita com significados, iniciando, nessa fase, a interpretação de sua escrita e a intenção de comunicá-la ao leitor.

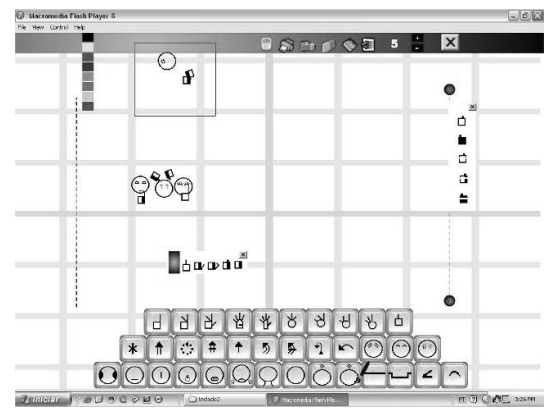

Figura 7. AO escrevendo com as teclas virtuais três sinais: papai, urso e mamãe.

JS avançou para a escrita com significados, assim como AO, contudo EM permaneceu na fase do desenho e a escrita, mas avançou para a escrita de seu sinal, como já mencionamos. MV iniciou seu processo nessa fase em que se encontrava JS e AO. Contudo, observamos que MV mantinha um vocabulário mais extenso, com sinais mais complexos e com domínio e clareza de sinais compostos. Suas frases eram mais complexas, ricas em detalhes e utilizava, em vários momentos, classificadores para expressar suas idéias. Essa fase se caracterizou pela utilização dos símbolos em conjuntos, formando os sinais. JS e AO ainda utilizavam a ferramenta pincel juntamente com as teclas virtuais, já MV iniciou diretamente por meio da ferramenta das teclas virtuais, como verificamos na Figura 8:

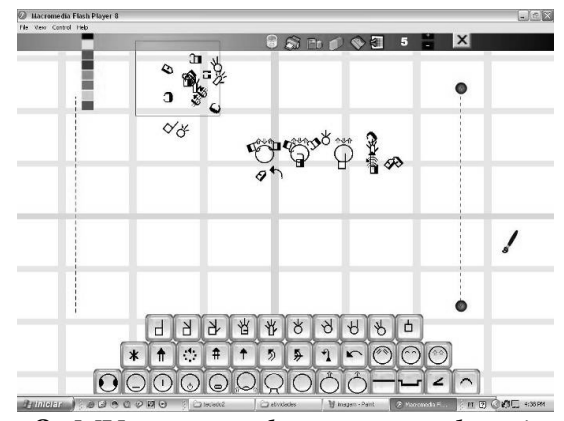

Figura 8. $M V$ escrevendo com as teclas virtuais uma frase, criando sinais compostos próprios, porém compreensíveis ao leitor.

\section{CONSIDERAÇÕES FINAIS}

Cada criança percorreu sua trajetória em seu próprio tempo e desenvolveu etapas que, em alguns momentos coincidiram, e em outros não, com as etapas de outros V. $7 \mathrm{~N}^{\circ}$ 3, dezembro, 2009 
sujeitos participantes da pesquisa. Casos como de JS permitem-nos levantar suposições de que a criança levanta hipóteses sobre sua escrita e, no caso de crianças surdas, ao fazerem a construção da escrita da língua de sinais, não se aproximam aos níveis sugeridos por Ferreiro e Teberosky, organizando-se de outras maneiras e sugerindo outras hipóteses. Verificamos que, mesmo sendo outro sistema de escrita e outro input para estas crianças, elas evoluem em etapas formulando hipóteses próprias para representar de forma gráfica uma linguagem visuo-gestual.

No decorrer das interações no ambiente digital do teclado virtual para escrita da língua de sinais, observamos que os sujeitos utilizaram em grande escala a ferramenta pincel quando estavam na etapa do desenho ou transitando entre o desenho e a escrita. A ferramenta pincel, tem em sua representação cultural, o desenho à mão livre ou a escrita à mão livre. A mediação por essa ferramenta permitiu ao sujeito explorar e apresentar a etapa em que se encontrava de forma livre, sem interferência de outras mediações, como a da pesquisadora. Verificamos que as teclas virtuais passavam a ser mais utilizadas quando o sujeito começava a estar ciente da capacidade de representar sua "fala" por meio da escrita. A ferramenta pincel começava a ser substituída pelas teclas virtuais, gradativamente.

$\mathrm{Na}$ escrita com significados, o sujeito iniciava o processo de interpretar sua escrita e preocupava-se em comunicar a mesma aos seus leitores, respeitando o mínimo de configurações que se tornariam um sinal comunicável e compreensível, o que seria possível com os símbolos selecionados no teclado.

Nesse momento, os sujeitos passavam a usar muito mais a ferramenta das teclas virtuais do que o próprio pincel utilizado para os desenhos das etapas anteriores. Ao ingressarem nessa etapa, as criancas passaram por um processo em que foram substituídos os traços nos quais não havia diferenciações, por desenhos e rabiscos e, posteriormente, por signos.

Com isso, verificamos que as crianças criam suas próprias hipóteses para resolver cada atividade proposta durante a evolução da escrita da língua de sinais. Podemos, assim, vislumbrar a necessidade de pesquisas mais longitudinais com grupos maiores de crianças de várias idades, em escolas que realmente se preocupem em inserir a cultura da escrita em seus cotidianos, já que este pequeno recorte de seis meses nos forneceu riquíssimas informações sobre a evolução da construção da escrita e da leitura em crianças surdas em ambientes digitais.

Com o avanço das pesquisas, conseguiremos reunir mais comprovações científicas e fundamentações teóricas para a necessidade emergencial desse processo, como na qualidade da construção do pensamento verbal de cada sujeito ao utilizarmos ferramentas pedagógicas (materiais concretos ou ambientes digitais) e metodologias de construção da escrita e leitura em língua de sinais mais adequados ao desenvolvimento lingüístico de crianzas surdas.

\title{
REFERÊNCIAS
}

\author{
Vygotski, L. S. - El Desarrollo de los Procesos Psicológicos Superiores - \\ Barcelo: Crítica, 2003.
}

Vigotski, L. S. - A construção do pensando e da linguagem - São Paulo: Martins Fontes, 2001. 
Daniels, H (Org.) - Vygotski em foco: pressupostos de desdobramentos. Campinas: Papirus Editora, 2003.

Fernandes, E. Surdez E Bilingüismo. Porto Alegre: Mediação, 2005

Quadros, R. M. - Aquisição de L1 e L2: o contexto da pessoa surda. In: Seminário: Desafios e Possibilidades na Educação Bilingüe para Surdos. Porto Alegre, 1997. Anais

Karnopp, L \& Quadros, R.M. de - Educação Infantil para surdos. In: Roman, E. D. \& Steyer V. E. (org). A crianza de 0 a 6 anos e a educação infantil: um retrato multifacetado. Canoas, 2001. Disponível em http://www.ronice.ced.ufsc.br/publicacoes/educacao.pdf

Ferreiro, E. \& Teberosky, A. - Psicogênese da Língua Escrita. Porto Alegre: Artes Médicas, 1999

Teberosky, A. - Construção de escritas através da interação grupal. In Ferreiro, E. \& Palacio, G.M. - Os processos de lectura e escrita. Porto Alegre: Artmed, 2003,

Silva, M. P. M. A Construção de Sentidos na Escrita do Aluno Surdo - São Paulo: Plexus Editora, 2001.

Capovilla, F. C. - Neuropsicologia e Aprendizagem Uma Abordagem Multidisciplinar. 2a Ed. São Paulo: Memnon 2004.

Stumpf, M. Aprendizagem De Escrita De Língua De Sinais Pelo Sistema Signwriting: Línguas De Sinais No Papel e no Computador. Porto Alegre: Ufrgs, 2005. Tese (Doutorado Em Informática Na Educação), Pós-Graduação Em Informática Na Educação, Universidade Federal Do Rio Grande Do Sul, 2005.

Stumpf, M. Sistema Signwriting: Por Uma Escrita Funcional Para O Surdo. In: Thoma, A. S. Et Al. A Invenção Da Surdez: Cultura, Alteridade, Identidade E Diferença No Campo Da Educação. Santa Cruz Do Sul: Edunisc, 2004.

Quadros, R. M. A Alfabetização e o Ensino da Língua de Sinais. Canoas: Textura, $\mathrm{N}^{\circ}$ 3, P. 53-62, 2000 